\title{
Validation of the Hunt Squash Accuracy Test used to assess individual shot performance
}

\author{
Benjamin Kane Williams ${ }^{1,2,}{ }^{*}$, Pitre Collier Bourdon ${ }^{1,3}$, Philip Graham-Smith ${ }^{1}$, and Peter J. Sinclair ${ }^{2}$ \\ 1 Aspire Academy, Sport Science Department, Doha, Qatar \\ 2 The University of Sydney, Discipline of Exercise and Sport Science, Sydney, Australia \\ ${ }^{3}$ University of South Australia, School of Health Sciences, Adelaide, Australia
}

Received 13 June 2016, Accepted 22 November 2016

\begin{abstract}
This study examined the validity of the Hunt Squash Accuracy Test (HSAT) for predicting withingame shot performance and tournament rank. Shots from eight male junior squash players performing the HSAT and tournament match-play were analysed. A typical-error analysis from repeated trials showed the HSAT to be very reliable $(1.82 \%)$. HSAT rank had significant correlations $(p<0.05)$ to tournament rank $(r=0.98)$ and tournament shot success $(r=0.95)$. HSAT score showed significant correlations to the percentage of winning shots during match-play $(r=0.88)$. HSAT shots with significant correlations to successful matchplay shots were backhand-drive $(r=0.92)$ and backhand-volley $(r=0.97)$. These results suggest the HSAT is a valid method of assessing the accuracy and performance of junior squash players. It could potentially be used to track shot improvements and predict match-play performance.
\end{abstract}

Key words: performance analysis, validity, error, reliability

Résumé-Validation du «Hunt Squash Accuracy Test » pour évaluer la performance des joueurs dans l'exécution de leurs coups. Cette étude porte sur la capacité du «Hunt Squash Accuracy Test» (HSAT) à prédire la performance des coups réalisé au cours d'un match de squash et le classement obtenu dans un tournoi par un joueur. Les coups de huit joueurs de squash juniors réalisés au cours du HSAT et lors d'un tournoi ont été analysés. L'analyse de l'écart type à la moyenne des essais répétés montre une très bonne fiabilité du HSAT (1,82\%). Le classement prédit par le HSAT est significativement corrélée $(p<0,05)$ avec le classement obtenu lors du tournoi $(r=0,98)$ et le nombre de coups réussis dans ce tournoi $(r=0,95)$. Une corrélation significative est également observée entre le score obtenu lors du HSAT et les coups gagnants réalisés lors du match $(r=0,88)$. Les coups spécifiques réalisés lors du HSAT présentant une corrélation avec des coups gagnants observés au cours du match sont les coups en revers $(r=0,92)$ et en volée de revers $(r=0,97)$. Ces résultats suggèrent que le HSAT est une méthode valide pour estimer la précision des coups et le niveau de performance de joueurs de squash juniors. Potentiellement, ce test pourrait être utilisé pour identifier les améliorations des coups réalisés par les joueurs et prédire le niveau de performance dans un tournoi de squash.

Mots clés : analyse de la performance, validité, fiabilité, erreur

\section{Introduction}

In a squash match, points can be won by accurately hitting to a strategically advantageous part of the court, thereby putting an opponent out of position such that they are unable to return the ball successfully (Lees, 2003). This results in squash being both a very technical and tactical game (Vučković, Perš, James, \& Hughes, 2009). Given the rules of squash, a successful shot could be considered one that is struck before the second bounce and reaches the

\footnotetext{
*Corresponding author: ben.williams@aspire.qa
}

front wall without touching any part of the court that is outside the area of play. Therefore, an advantageous successful shot would be a shot that prevents an opponent from achieving a subsequent successful shot.

Within a squash rally there are three main means by which a point may be won or lost; hitting a winning shot (winner), performing an unforced error, or making a forced error. Although these three terms are quite common in the racket-sport literature, they are often not consistently defined. Reid et al. (2013) measured both unforced and forced errors while evaluating the effect of tennis-court surface on technical performance, however neither term was 
defined. Strecker, Foster, and Pascoe (2011) described tennis unforced errors as the execution of errors that a player should not have executed, but did not establish how that was defined. In contrast, Hughes and Meyers (2005) gave definitions for all possible outcomes from a rally in tennis.

Using the limited published definitions to summarise; a winner could be described as a ball that is hit accurately, with the right amount of speed, into a strategically advantageous position relative to where the opponent is located, such that the opponent is unable to hit the ball before the second bounce. A forced error could be similar to the definition of a winner, however the opposing player was able to hit the ball but not able to keep the ball in play. Finally, an unforced error could be described as an error which is deemed to be the fault of the player on a shot that would normally be returned. Ultimately, even with the above definitions, these classifications are still somewhat subjective.

Improvements in sport performance can be partly attributed to increased training quality as assessed by sport-specific testing (Müller, Benko, Raschner, \& Schwameder, 2000). The development of valid reproducible tests that assess athlete strengths and weaknesses therefore become a necessity (Wilkinson, Leedale-Brown, \& Winter, 2009). It has been established that three types of validity can be applied to performance protocols; logical - the ability to assess components known to be important to performance; criterion - comparison to a "gold standard"; and construct - the ability to discriminate between groups of performers with different abilities (Currell \& Jeukendrup, 2008; Wilkinson, et al., 2009; Winter, Jones, Davison, Bromley, \& Mercer, 2007). For a sport-specific test to be valid for assessment purposes and of value in tracking performance it must also demonstrate good reproducibility (National Coaching Foundation, 1995).

The accuracy of squash shots has received almost no attention in the literature. The ability to hit a shot accurately is an important fundamental skill for squash players and one that is developed over time (Ariff, Osman, \& Usman, 2012). The ability to reliably assess this skill is paramount in the development of players. One of the few studies involving a form of squash accuracy test was Bottoms, Hunter, and Galloway (2006), who used a skill test to help evaluate the effect of carbohydrate ingestion on squash players. The test involved hitting a straightdrive down the wall with the aim of it bouncing in a predefined target area behind the service box. Points were allocated depending on which area of the target the ball bounced in. The authors stated the test was reliable and had a significant inverse relationship between test score and player ranking. While there is some literature in other racket sports such as tennis (Strecker, et al., 2011), badminton (Sakurai \& Ohtsuki, 2000) and table tennis (Aune, Ingvaldsen, \& Ettema, 2008), as yet there appears to be very little assessing this important skill for squash players.

One test that is currently used by some squash coaches to assess this technical aspect of squash is the "Hunt Squash Accuracy Test" (HSAT) (Williams, Hunt,
Graham-Smith, \& Bourdon, 2014). The HSAT evaluates an athlete's hitting accuracy over 13 different types of squash strokes on both the forehand and backhand sides. A previous study by Williams et al. (2014) showed that the total score on the HSAT had large and significant correlations to both tournament rank and expert coach rank. However, there has been no evaluation on whether scoring well on a particular shot on the HSAT equates to good performance of the same shot within a match, or how the total HSAT score relates to squash match performance. Therefore the aim of this study was to quantify the relationship between the scores from the HSAT and the success of shots played within tournament match-play and to assess whether the HSAT score reflects player tournament rank.

\section{Methods}

\subsection{Participants}

Eight male junior squash players aged $15.5 \pm 1.8$ years, with height $1.68 \pm 0.10 \mathrm{~m}$ and body mass $61.9 \pm 14.6 \mathrm{~kg}$, from a national sports academy volunteered to participate in the study. All participants were ranked in the top 3 in their nation for their respective age groups, were free from injury at the time of testing and reported no limitations or discomfort throughout the tests. All participants had experience in performing the HSAT, having previously performed the test a minimum of three times (average $8.1 \pm 4.4$ ). All participants gave written informed consent before participating in the study, which was approved by The University of Sydney Human Research Ethics Committee (project number 2014/784).

\subsection{Equipment set-up}

All testing and tournament matches took place at an indoor squash training facility on one of two standard glass-back squash courts (ASB SquashCourts, Czech Republic). The players used their own racket throughout the study. A camera (Sony HDR-XR260VE, Sony Corporation, Japan) mounted on a tripod (Sony VCT$80 \mathrm{AV}$ ) was positioned $1.4 \mathrm{~m}$ above the ground and $7.0 \mathrm{~m}$ from the centre of each squash court. Each match was filmed at $25 \mathrm{~Hz}$ in high-definition.

\subsection{Testing procedure}

All HSAT assessments were conducted by an experienced coach who had been running the test with the squad for over 3 years. Each player performed a standard pregame warm-up prior to the start of the test. The ball was warmed up appropriately and kept in a state of "match readiness" throughout the test. The test protocol and number of shots is outlined in Table 1. The target areas for each shot type are shown in Figure 1. With respect to the participant's individual style, players were not limited to a particular stance or technique, however they were requested to perform each shot at a speed similar to that within a game. 
Table 1. Shot type, number and corresponding definitions for the HSAT.

\begin{tabular}{|c|c|c|}
\hline Shot type & $\begin{array}{l}\text { No. } \\
\text { of shots }\end{array}$ & Definition \\
\hline $\begin{array}{l}\text { Drive down the middle } \\
\text { (Drive Middle) }\end{array}$ & 50 & $\begin{array}{l}\text { Hit continuously to self anywhere on the court; the ball must hit the back door } \\
\text { ( } 0.9 \mathrm{~m} \text { wide) after bouncing once, then be played again (the first hit is not counted) }\end{array}$ \\
\hline Volley drive (Volley) & 25 & $\begin{array}{l}\text { Hit continuously to self from the half-court line, within the service box; the ball } \\
\text { must not touch the side wall and must be hit within } 1 \mathrm{~m} \text { of the side wall (the first } \\
\text { hit is not counted) }\end{array}$ \\
\hline Volley drop & 25 & $\begin{array}{l}\text { Standing at the "T", the ball is fed to the player, who must play a volley shot; the } \\
\text { ball's } 2 \text { nd bounce must land within } 0.35 \mathrm{~m} \text { from the side wall and } 1 \mathrm{~m} \text { before the } \\
\text { half-court line }\end{array}$ \\
\hline Boast & 25 & $\begin{array}{l}\text { The ball is fed to the player via a straight drive shot approximately } 0.5 \mathrm{~m} \text { from the } \\
\text { side wall, then, after ball hits the back wall, the player hits a boast (hits the ball } \\
\text { into the near side wall, then front wall); the ball's } 2 \text { nd bounce must be within } 0.7 \mathrm{~m} \\
\text { from the opposite side wall and } 1 \mathrm{~m} \text { before the half-court line }\end{array}$ \\
\hline Volley mixed & 25 & $\begin{array}{l}\text { Standing behind the "T", one foot must stay either side of the mid-court line; the } \\
\text { ball is hit with alternate forehand and backhand shots continuously without hitting } \\
\text { the floor (the first hit is not counted). }\end{array}$ \\
\hline
\end{tabular}

Markers were placed on the court at the specific points (described in Tab. 1) for each of the shot types to designate the target areas. Each shot type was performed on both the forehand and backhand side for all shots except the "volley mixed" (as that incorporates alternating forehand and backhand shots). Where appropriate, the coach fed the ball to each player to ensure consistency. The players had approximately $30 \mathrm{~s}$ between each different stroke test and 3-5 s between feeds for the boasts and drop-shots. A complete test took approximately $30 \mathrm{~min}$ in total. A score was accrued based on the number of shots landing in the target areas and was recorded by the coach on a score sheet.

The tournament commenced one day after all the participants had completed the HSAT. The tournament was run in a round-robin format, where every player played a best-of-5-game match against every other player. All matches were conducted as per the World Squash Federation (WSF) international singles rules (World Squash Federation, 2013) and refereed by an experienced coach. Players performed a standard pregame warm-up before each match. All matches were conducted during the squad's regular training times with a total of 2 matches per day maximum. The order of play was random. All tournament matches were completed within 5 days, which aligns with international tournament play.

\subsection{Data analysis}

The scores from the HSAT were converted to percentages using the formula: number of shots landing in the target area/total number of shots $\times 100$. A total overall score (percentage) was calculated by summing all 13 specific shot scores and dividing this by the total number of shots played, multiplied by 100. A total score was also calculated for all the backhand and forehand shots separately (backhand-HSAT and forehandHSAT).

A tournament rank was obtained from the results of the tournament. Each video file from the tournament was imported into Dartfish TeamPro software (Dartfish TeamPro version: 7.0). Every shot played by both players in each game from all the matches was then tagged using the following descriptors:

- Shot side: forehand; backhand;

- Shot type: drive; volley; boast; volley-drop; drop; lob; serve (Tab. 2);

- Shot direction: straight; cross-court;

- Outcome: rally continues; winner; unforced-error, forced-error (Tab. 3).

The definitions shown in Table 2 were used to describe the shot type (Hughes \& Meyers, 2005). The definitions in Table 3 were used to describe the outcomes of the rally (Hughes \& Meyers, 2005). A let was considered as a "rally continues" as the point was neither won nor lost, but replayed. A stroke was considered either a forced error or unforced error depending on the situation in which it was awarded by the referee. Each of the different shot types was then converted into a percentage using the formula: total number of shots - unforced errors/total number of shots $\times 100$, to give the success for each of the specific shot types. The total number of shots did not include forced errors, as by definition they were the result of an opponent's shot that led to a difficult and unreturnable shot to play. 
Table 2. Definitions of shot types.

\begin{tabular}{ll}
\hline Shot & Definition \\
\hline Drive & A shot played after the ball has bounced off the floor and is hit at the front wall with speed \\
Volley & A shot hit before the ball has bounced off the floor \\
Boast & A shot played such that the ball hits a side or back wall before the front wall \\
Drop & A shot that is hit such that the ball hits the front wall (gently) and lands close to the front wall \\
Volley-Drop & A shot hit before the ball has bounced off the floor such that it hits the front wall (gently) and lands close to \\
Lob & the front wall
\end{tabular}

Table 3. Definitions of rally outcomes.

\begin{tabular}{ll}
\hline Outcome & Definition \\
\hline Rally continues & The shot played results in the rally continuing - the ball is returned by the opponent \\
Winner & A shot that results in winning the point, that was unplayable or untouched by the opponent before the \\
second bounce & An error which is deemed to be the fault of the player on a shot that would normally be returned \\
Fnforced error & An error which results from an opponent's shot, leading to a difficult shot to play, which causes an error \\
\hline
\end{tabular}

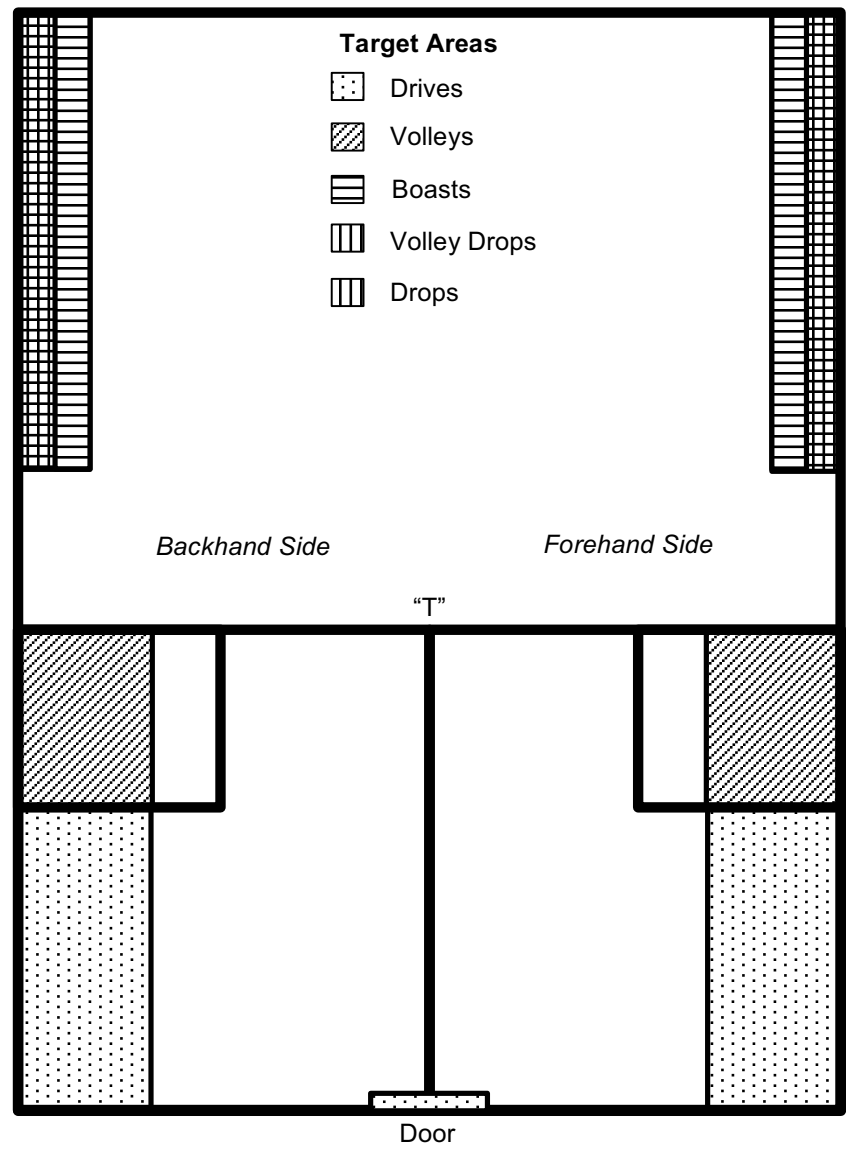

Fig. 1. HSAT target areas for the various strokes. Refer to Table 1 for target area dimensions.

The following performance variables were chosen for analysis and comparison to the HSAT scores and tournament rank. These variables were chosen because they were hypothesised to be the most likely to be associated with the HSAT scores and player performance.
- Shot success: percentage success ((total number of shots - number of unforced errors)/total number of shots $\times 100$ ) per shot type.

- Mean number of shots per person: mean number of shots played per person for each shot type within the tournament (7 matches).

- Unforced errors: percentage of unforced errors per shot type.

- Winning Shots: percentage of winning shots ((number of shots that preceded a forced error by an opponent + number of winners)/total number of shots $\times 100$ ) per shot type.

- Tournament rank.

\subsection{Reliability}

The reliability of the HSAT was determined via a typical error (TE) analysis from repeated trials (standard deviation of the differences between trials divided by the square root of 2) in which all participants performed the HSAT twice within 7 days (Hopkins, 2000). The reliability data were collected during a pilot study conducted prior to the commencement of the tournament (Williams, et al., 2014). In addition to the reliability of the test, the analyst's reliability for determining shot outcomes was also determined via a TE analysis. Ten matches from the tournament were randomly selected for repeat analysis. The resultant TE's for the derived performance analysis variables were subsequently used as a measure of the error within the analysis process.

\subsection{Statistical analysis}

The reliability data were assessed using spreadsheets from Hopkins (2015). All other data analysis were done using SPSS Statistics software (IBM, version 22). 
Table 4. Typical Error scores and 95\% confidence intervals (CI) of the typical error for the HSAT score.

\begin{tabular}{llcc}
\hline Shot type & Typical error & Typical error & $95 \%$ CI \\
& Number of shots (shots) & Percentage of total shots (\%) & Number of shots (shots) \\
\hline Forehand Drive Middle & 3.48 & 6.96 & $2.39-6.35$ \\
Backhand Drive Middle & 1.66 & 3.32 & $1.14-3.03$ \\
Forehand Drive Back & 1.45 & 5.80 & $1.00-2.65$ \\
Backhand Drive Back & 1.17 & 4.68 & $0.80-2.13$ \\
Forehand Volley Drive & 1.54 & 6.16 & $1.06-2.82$ \\
Backhand Volley Drive & 1.64 & 6.56 & $1.13-3.00$ \\
Forehand Volley Drop & 2.09 & 8.36 & $1.44-3.81$ \\
Backhand Volley Drop & 2.32 & 9.28 & $1.60-4.24$ \\
Forehand Boast & 1.50 & 6.00 & $1.03-2.74$ \\
Backhand Boast & 2.52 & 10.08 & $1.73-4.60$ \\
Forehand Drop & 1.47 & 5.88 & $1.01-2.68$ \\
Backhand Drop & 1.83 & 7.32 & $1.26-3.34$ \\
Volley mixed & 0.97 & 3.88 & $0.67-1.77$ \\
Overall \% score & - & 1.82 & $1.25-3.32$ \\
\hline
\end{tabular}

The matching shot types from the HSAT and performance analysis data (10 different shots) were analysed using Pearson product-moment correlation coefficients after checking the normality of distribution for each variable. Players were ranked on their HSAT, shot success and winning shots score, with the association between those variables and tournament ranking assessed using Spearman's correlation analysis. Significance was set at $p<0.05$. Confidence intervals (CI) were determined using the SPSS bootstrapping module (Weaver \& Koopman, 2014). Correlation effect sizes were considered as small $( \pm 0.1$ to \pm 0.29$)$, medium $( \pm 0.3$ to \pm 0.49$)$ and large $( \pm 0.5$ to \pm 1.0$)$ (Cohen, 1988).

\section{Results}

\subsection{Reliability}

The TE scores from the repeated HSAT trials are presented in Table 4. Furthermore, the analyst's reliability was found to range from a TE score of $0-0.77$ shots for all of the derived performance analysis variables analysed.

\subsection{Data analysis}

The Spearman's $r$ value for tournament rank compared to HSAT rank was $0.98(p=0.00,95 \% \mathrm{CI}=0.73-$ 1.00) and compared to winning shots ranking was 0.95 $(p=0.00,95 \% \mathrm{CI}=0.62-1.00)$. The Pearson's $r$ value for the winning shots score compared to total HSAT score was $0.88(p=0.00,95 \% \mathrm{CI}=0.80-0.98)$. The individual participant's tournament rank and total shot success score within the tournament can be seen plotted against total HSAT rank and score respectively in Figure 2. The mean number of shots per person $( \pm s)$ during the entire tournament; Pearson's $r$ values for each of the specific shot type's success compared to the corresponding score from the HSAT; and Spearman's $r$ values for specific shot type's success and tournament rank are shown in Table 5.

\section{Discussion}

The HSAT aims to assess one of the technical elements of the game of squash, the player's shot hitting accuracy. The overall TE score of the test demonstrates that it is very reliable (Tab. 4). This research compares favourably with the research of Strecker et al. (2011), who showed good reliability, with no significant difference between test-retest scores, for a tennis hitting accuracy test. The higher errors associated with the Backhand Boast, Forehand and Backhand Volley Drop could indicate that these are more difficult shots to hit accurately and therefore introduced more variation between tests.

The correlation analyses indicate a large and significant correlation between the HSAT rank and tournament rank. This finding confirms a previous study where Williams et al. (2014) similarly found a large and significant correlation between those variables $(r=0.93)$. This finding suggests that the HSAT can discriminate overall squash player ability for junior athletes and that the test possesses construct validity (Currell \& Jeukendrup, 2008). These results also compare favourably with that of other specific validation studies, such as Wilkinson et al. (2009), who showed that a squash specific change-of-direction speed test significantly correlated $(r=0.77)$ with squash player rank.

Furthermore, it appears that not only can the HSAT discriminate player ability, but also overall shot performance within match-play, as evidenced by the large and significant correlation between total HSAT score and within-game shot success (Fig. 2(b)). Similarly, both the backhand-HSAT and forehand-HSAT scores were also 
Table 5. Shot success correlations for specific shot types compared to HSAT scores and tournament rank.

\begin{tabular}{|c|c|c|c|c|c|c|c|c|}
\hline \multirow[t]{2}{*}{ Shot type } & & \multirow{2}{*}{$\begin{array}{l}\text { Mean number of } \\
\text { shots per person } \\
\text { Mean } \pm s\end{array}$} & \multicolumn{3}{|c|}{$\begin{array}{l}\text { Pearson's correlations between in-game } \\
\text { success and HSAT scores }\end{array}$} & \multicolumn{3}{|c|}{$\begin{array}{l}\text { Spearman's correlations between in-game } \\
\text { success rank and tournament rank }\end{array}$} \\
\hline & & & $r$-Value & $p$-Value & $95 \% \mathrm{CI}$ & $r$-Value & $p$-Value & $95 \%$ CI \\
\hline \multirow[t]{2}{*}{$\overline{\text { Drive }}$} & $\mathrm{BH}$ & $137 \pm 30$ & 0.92 & $0.00^{*}$ & $0.75-0.99$ & 0.93 & $0.00^{*}$ & $0.60-1.00$ \\
\hline & FH & $62 \pm 20$ & 0.64 & 0.09 & $0.11-0.92$ & 0.79 & $0.02^{*}$ & $0.17-1.00$ \\
\hline \multirow[t]{2}{*}{ Boast } & $\mathrm{BH}$ & $30 \pm 16$ & 0.28 & 0.50 & $-0.33-0.86$ & 0.60 & 0.12 & $-0.27-1.00$ \\
\hline & FH & $27 \pm 10$ & 0.15 & 0.72 & $-0.48-0.98$ & 0.50 & 0.21 & $-0.52-1.00$ \\
\hline \multirow[t]{2}{*}{ Volley } & $\mathrm{BH}$ & $34 \pm 11$ & 0.97 & $0.00^{*}$ & 0.89-1.00 & 0.81 & $0.02^{*}$ & 0.11-1.00 \\
\hline & FH & $14 \pm 5$ & 0.46 & 0.26 & $-0.49-0.98$ & 0.32 & 0.44 & $-0.54-0.98$ \\
\hline \multirow[t]{2}{*}{ Volley-Drop } & $\mathrm{BH}$ & $13 \pm 5$ & 0.37 & 0.37 & $-0.91-0.85$ & -0.16 & 0.71 & $-0.97-0.75$ \\
\hline & FH & $5 \pm 4$ & 0.53 & 0.17 & $-0.47-0.98$ & 0.44 & 0.27 & $-0.47-0.98$ \\
\hline \multirow[t]{2}{*}{ Drop } & $\mathrm{BH}$ & $35 \pm 14$ & 0.14 & 0.74 & $-0.44-0.79$ & -0.20 & 0.63 & $-0.83-0.80$ \\
\hline & $\mathrm{FH}$ & $16 \pm 9$ & 0.62 & 0.10 & 0.16-0.91 & 0.83 & $0.01^{*}$ & $0.32-1.00$ \\
\hline \multirow{2}{*}{ Combined shots } & $\mathrm{BH}$ & $249 \pm 39$ & 0.94 & $0.00^{*}$ & $0.76-0.99$ & 0.98 & $0.00^{*}$ & $0.80-1.00$ \\
\hline & $\mathrm{FH}$ & $123 \pm 18$ & 0.77 & $0.03^{*}$ & $0.36-0.99$ & 0.76 & $0.03^{*}$ & $0.04-1.00$ \\
\hline Total all shots & & $372 \pm 40$ & 0.90 & $0.00^{*}$ & $0.73-0.99$ & 0.95 & $0.00^{*}$ & $0.62-1.00$ \\
\hline
\end{tabular}

Note. Backhand $=\mathrm{BH}$, Forehand $=\mathrm{FH}$.

(a) Tournament Rank v HSAT Rank

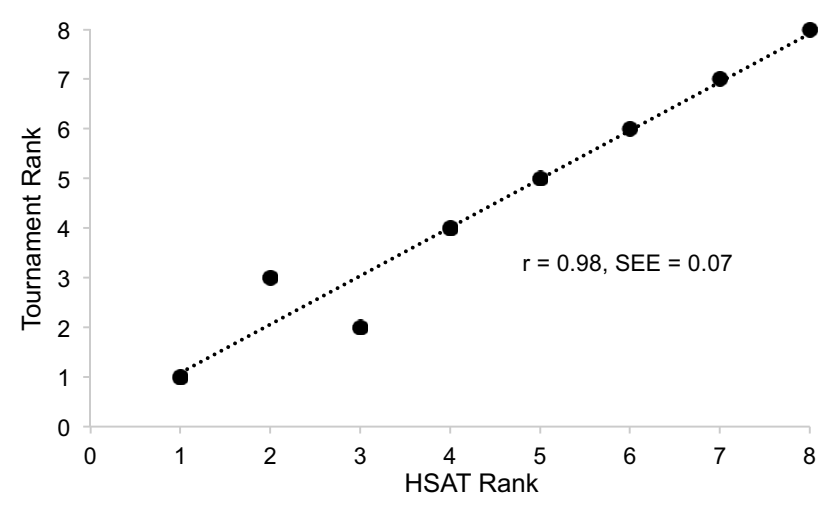

(b) Shot Success v HSAT Score

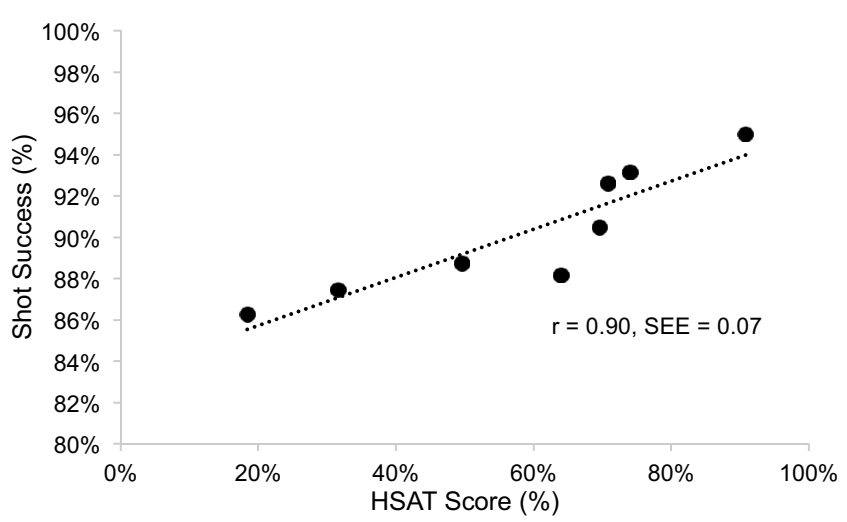

Fig. 2. Performance results: (a) tournament rank plotted against HSAT Rank and (b) shot success plotted against total HSAT score for each participant $(\mathrm{SEE}=$ standard error of the estimate). found to have large and significant correlations with combined backhand shot success and combined forehand shot success respectively (Tab. 5).

The performance analysis variables used in this study incorporated match-pressure and were a direct measure of a player's ability to successfully hit the ball during a competitive game. The large and significant correlations found between tournament rank and shot success rank of the backhand drive, forehand drive, backhand volley and forehand drop suggest that those strokes have a high influence on the overall success within a match and tournament (Tab. 5). Of those shots, the backhand drive and backhand volley were shown to have large and significant correlations to the specific HSAT scores, implying that those individual scores can be directly related to performance. The high mean number of shots per person on the backhand drive (23\% of all shots) compared to the other shots concurs that this is one of the most commonly played shots during a squash match (Vučković, et al., 2013). The large correlation to tournament rank and high shot count also suggests that the ability to hit this shot accurately is important to the success within a match and tournament (Tab. 5).

Although not significant, the forehand drive, forehand volley-drop and forehand drop also showed large correlations between shot success in match-play and HSAT scores (Tab. 5). Perhaps with a larger sample size significance may have been achieved. It is possible that the weaker correlations for the other HSAT shot results compared to the shot success within a match were caused by the players favouring their more accurate shot types, in order to maintain a rally. Players may only play certain less accurate shots when either forced to (due to positioning on the court) or when it is advantageous to do so (trying to hit a winner). It is also possible that certain players take more risks than others, thereby trying to hit more winners and perhaps chancing less accurate shots 
earlier in the rally rather than playing a more accurate, less difficult shot. This would increase the chance of more unforced errors and decrease their shot success percentage compared to the non-competitive HSAT score. This is not something that could be controlled for and would depend on the style of play of a player, or the type of match they were playing.

Although there was no velocity data collected during this study, it is possible that, similar to Landlinger, Stöggl, Lindinger, Wagner, and Müller (2011), the better players were hitting the ball at a higher velocity within games. If this were the case, although they could have similar within-game shot success scores as some weaker players, if they were hitting the ball faster it could have created more winners or forced errors in their opponents by reducing the amount of time available to return the ball. It is also possible that due to having less time between shots, an opponent may have had to play a different shot, or a tactically weaker shot than normal, thereby giving the better player more advantage to win the point (Vučković, et al., 2013). This could be an area for further research.

Certain limitations of the HSAT became apparent during this study. Match-play shots which could not be compared to HSAT scores included all serves, lobs and cross-court shots (36\% of shots analysed) as there was no corresponding HSAT shot. Another potential limitation is that, although the participants were requested to perform all shots at a similar speed to shots played within a game, there was no measure of this during the HSAT. It is possible that during the HSAT the ball speeds were reduced slightly in order to increase accuracy. This could account for potential differences in the HSAT accuracy results and within-game success results.

The HSAT evaluates shot hitting accuracy, however it does not take into account the potential differences in the mechanics of the shot strokes or racket parameters, which can be of paramount importance in squash (Elliott, Marshall, \& Noffal, 1996). The HSAT is performed in a relatively controlled environment where the player knows where the ball will be and therefore has enough time to set themselves to perform the designated stroke without much pressure. The ball velocity and direction, body position and swing kinematics could all potentially change under match pressure when trying to win a point. It is therefore recommended that a kinematic analysis be undertaken during the performance of the HSAT and a match to compare the biomechanics of accurate and inaccurate shots. This could further assist in determining the reasons for any differences between shot accuracy and also assist in the development of shot technique and skill.

While the only HSAT shots to show a significant correlation to the success of match shots were the backhand drive and backhand volley, which also had large significant correlations to tournament rank, there were possible trends for a number of other shots. These suggest that future investigations using larger participant numbers, players of different age, sex and ability may further validate the HSAT.

\section{Conclusion}

The results of this study show that the HSAT is a reliable and valid method of assessing the accuracy and performance of junior squash players when compared to performance at a tournament. The high mean shot count and large significant correlations between shot success and HSAT score to tournament rank of the backhand drive also demonstrate the importance of being able to play that shot accurately and consistently. The HSAT could be used by coaches to track the performance improvements of developing players, or quantify the effectiveness of a training intervention that aims to improve the accuracy of shots.

The authors would like to thank the Aspire Academy Head Squash Coach Stewart Boswell for his assistance with the data collection.

\section{References}

Ariff, F.H.M., Osman, N.A.A., \& Usman, J. (2012, July). Joint angle production during squash forehand and backhand stroke. Paper presented at the 30th Annual Conference of Biomechanics in Sports, Melbourne, Vic, Australia.

Aune, T.K., Ingvaldsen, R.P., \& Ettema, G.J.C. (2008). Effect of physical fatigue on motor control at different skill levels. Perceptual and Motor Skills, 106(2), 371-386.

Bottoms, L.M., Hunter, A.M., \& Galloway, S.D.R. (2006). Effects of carbohydrate ingestion on skill maintenance in squash players. European Journal of Sport Science, 6(3), 187195.

Cohen, J. (1988). Statistical power analysis for the behavioral sciences (2nd ed.). Hillsdale, NJ: L. Erlbaum Associates.

Currell, K., \& Jeukendrup, A.E. (2008). Validity, reliability and sensitivity of measures of sporting performance. Sports Medicine, 38(4), 297-316.

Elliott, B., Marshall, R., \& Noffal, G. (1996). The role of upper limb segment rotations in the development of racket-head speed in the squash forehand. Journal of Sports Sciences, 14 (2), 159-165.

Hopkins, W.G. (2000). Measures of reliability in sports medicine and science. Sports Medicine, 30(1), 1-15.

Hopkins, W.G. (2015). Spreadsheets for analysis of validity and reliability. Sportscience, 19, 36-42. Retrieved from sportsci. org/2015/ValidRely.htm.

Hughes, M., \& Meyers, R. (2005). Movement patterns in elite men's singles tennis. International Journal of Performance Analysis in Sport, 5(2), 110-134.

Landlinger, J., Stöggl, T., Lindinger, S., Wagner, H., \& Müller, E. (2011). Differences in ball speed and accuracy of tennis groundstrokes between elite and high-performance players. European Journal of Sport Science, 12(4), 301-308.

Lees, A. (2003). Science and the major racket sports: a review. Journal of Sports Sciences, 21(9), 707-732.

Müller, E., Benko, U., Raschner, C., \& Schwameder, H. (2000). Specific fitness training and testing in competitive sports. Medicine and Science in Sports and Exercise, 32(1), $216-220$.

National Coaching Foundation. (1995). A guide to field based fitness testing. Leeds, United Kingdom: The National Coaching Foundation. 
Reid, M.M., Duffield, R., Minett, G.M., Sibte, N., Murphy, A.P. \& Baker, J. (2013). Physiological, perceptual, and technical responses to on-court tennis training on hard and clay courts. Journal of Strength and Conditioning Research, 27(6), 14871495.

Sakurai, S., \& Ohtsuki, T. (2000). Muscle activity and accuracy of performance of the smash stroke in badminton with reference to skill and practice. Journal of Sports Sciences, 18 (11), 901-914.

Strecker, E., Foster, E.B., \& Pascoe, D.D. (2011). Test-retest reliability for hitting accuracy tennis test. Journal of Strength and Conditioning Research, 25(12), 3501-3505.

Vučković, G., Perš, J., James, N., \& Hughes, M. (2009). Tactical use of the $\mathrm{T}$ area in squash by players of differing standard. Journal of Sports Sciences, 27(8), 863-871.

Vučković, G., James, N., Hughes, M., Murray, S., Sporiš, G., \& Perš, J. (2013). The effect of court location and available time on the tactical shot selection of elite squash players. Journal of Sports Science 8 Medicine, 12(1), 66-73.
Weaver, B., \& Koopman, R. (2014). An SPSS macro to compute confidence intervals for Pearson's correlation. The Quantitative Methods for Psychology, 10(1), 29-39.

Wilkinson, M., Leedale-Brown, D., \& Winter, E.M. (2009). Validity of a squash-specific test of change-of-direction speed. International Journal of Sports Physiology and Performance, $4(2), 176-185$.

Williams, B.K., Hunt, G.B., Graham-Smith, P., \& Bourdon, P. C. (2014, July). Measuring squash hitting accuracy using the 'Hunt Squash Accuracy Test'. Paper presented at the 32nd Conference of the International Society of Biomechanics in Sports, Johnson City, TN, United States of America.

Winter, E.M., Jones, A.M., Davison, R.R., Bromley, P.D., \& Mercer, T.H. (Eds.). (2007). Sport and exercise physiology testing guidelines (Vol. I: Sport testing). Abingdon, United Kingdom: Routledge.

World Squash Federation. (2013). World squash singles rules 2014. East Sussex, United Kingdom: World Squash Federation Ltd.

Cite this article as: Williams BK, Bourdon PC, Graham-Smith P, \& Sinclair PJ (2017) Validation of the Hunt Squash Accuracy Test used to assess individual shot performance. Mov Sport Sci/Sci Mot, 100, 13-20 